\title{
Sea surface temperature estimation using remotely sensed imagery of Landsat 8 along the coastline of Tangier - Ksar Sghir region
}

\author{
Imane Bourouhou ${ }^{1, *}$ and Farida Salmoun ${ }^{1}$ \\ ${ }^{1}$ Laboratory of Physical Chemistry of Materials, Natural Substances and Environment, Faculty of Sciences and Techniques, Abdelmalek \\ Essaadi University, Tangier, Morocco
}

\begin{abstract}
Seawater temperature is an extremely important factor as it affects the ecological balance of marines ecosystems, the continental weather, and the earth's atmosphere. However, the pressure on both coastal and marine resources, the use of oceans as a wastes deposit, the increase of urbanization, and anthropogenic activities in coastal zones are all causes of thermal pollution. The degradation of water quality by any process that changes ambient water temperature constitutes a significant danger in many coastal areas in the world. The region of Tangier-Ksar Sghir overlooking the Mediterranean Sea is experiencing growth of population and increasing urbanization and human activities, in addition to the industrial and touristic activities along the coastline. These activities are the main sources of thermal pollution that have effects on human health and the environment in the region. So, it is very important to examine seawater temperature in order to protect the marine and coastal areas from thermal pollution. In the current study, an approach based on TIRS thermal band data was used to estimate sea surface temperature. The results showed a good correlation between in-situ measurements and the estimated values from Landsat8 images along the coastline of the study area.
\end{abstract}

\section{Introduction}

The Mediterranean Sea plays a crucial role in maintaining the ecological balance of ecosystems and developing the economic wellbeing of the countries bordering it. Over $40 \%$ of the world's population lives in coastal regions and lake or river shores [1]. The region of Tangier-Ksar Sghir located on the Maghreb coast at the western entrance to the Strait of Gibraltar is experiencing growth of population and increasing urbanization and human activities, in addition to the industrial and touristic activities along the coastline. The present situation has a significant impact on the coastal water quality in this region.

Water temperature is one of the important parameters for the physical and biochemical processes occurring within the water as well as in air-water interactions because temperature regulates physical, chemical, and biological processes in water [2]. Sea surface temperature (SST) is also considered as an environmental factor for determining marine and coastal variation. Therefore, the thermal pollution of seawater involves serious dangers for coastal and marine ecosystems.

Thermal Infrared Remote sensing (TIR) is a branch of remote sensing with Infrared waves [3] that can provide reliable measurements of emitted radiation from the surface. Most importantly, it can significantly contribute to the assessment of thermal pollution. The application of remote sensing techniques can be an attractive alternative to studying water temperature when compared to traditional methods that are expensive, both in cost and time.

\section{Methodology}

\subsection{Study area}

The Tangier-Ksar Sghir is a coastal region placed in north Morocco. The capital city Tangier covers an area of $11,570 \mathrm{~km}^{2}$, representing $1.6 \%$ of the total area of the Moroccan Kingdom [4]. It is bordered by the Mediterranean Sea to the north, the Atlantic Ocean to the west, the region of Taza-Al Hoceima-Taounate to the east, and the Gharb-Chrarda-Beni Hssen South [5].

The region of Ksar-Sghir is mostly known by Tangier Med port. The port was built between 2004 and 2007. Its main activity is the transshipment of containers and it's connected to more than 120 ports in 50 countries around the. Geographically, the port is positioned on the east-west world shipping trade route between Asia, Europe, and North America, which is considered the second busiest sea lane in the world, with more than 100,000 boats per year.

\subsection{Data preparation}

Sensors present a powerful tool which can allow seawater researchers and decision-makers to assess water

\footnotetext{
*Corresponding author: ibourouhou@uae.ac.ma
} 
parameters efficiently. Remote sensing multi-concept helps to understand the natural environment, and managing water resources on local and regional levels [6]. Thermal infrared bands are used to measure the amount of infrared light emitted from the surface and the radiant temperature of water bodies. Estimated temperature acquired by remote sensing should be treated with great care when there are reasons to assume that the water is stratified [7]. Water temperature measurements can be obtained with a sensor that detects thermal radiation (3-5 and 8-14 $\mu \mathrm{m}$ wavebands) emitted from the upper $0.1 \mathrm{~m}$ of the water surface [8].

The following flowchart presented in figure 1 illustrates a step-by-step process followed in order to retrieve sea surface temperature (SST) from Landsat 8 images.

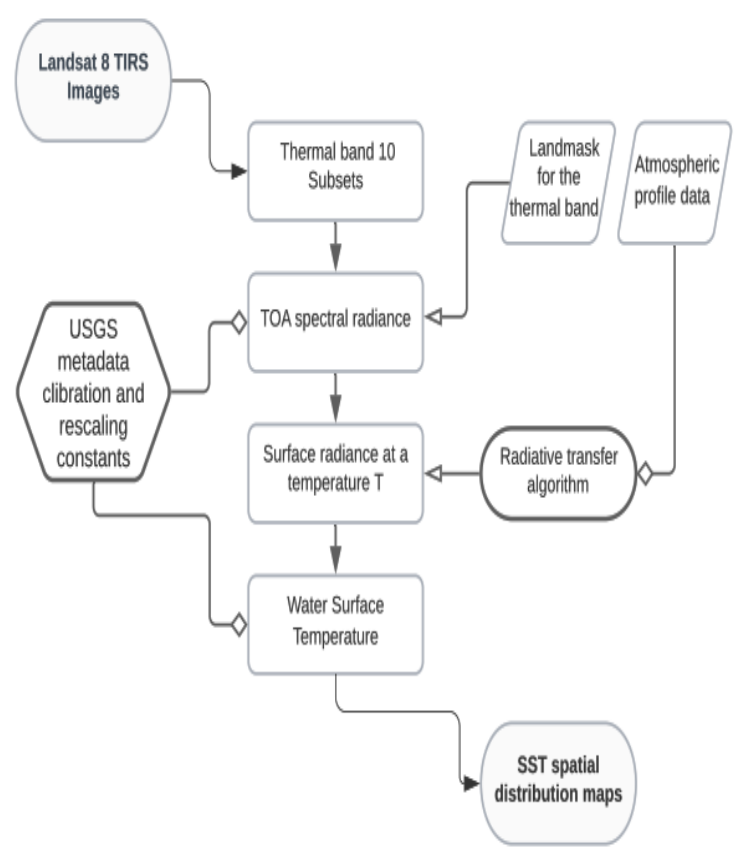

Figure 1. Flowchart for Sea Surface temperature retrieve from TIRS thermal band

The current study used the Landsat 8 Thermal Infrared Sensor (TIRS) data delivered in 16-bit. Landsat8 curries two sensors: - the Operational Land Imager (OLI) and the Thermal Infrared Sensor (TIRS). These two sensors provide seasonal coverage of the global landmass at a spatial resolution of 30 meters (visible, NIR, SWIR); 100 meters (thermal); and 15 meters (panchromatic) [9].

Landsat data are composed of quantized and calibrated scaled Digital Numbers (DN) which can be rescaled to the top of atmosphere (TOA) radiance using radiometric rescaling factors and thermal constants used to convert thermal band data to TOA brightness temperature (Table 1) [10]. These coefficients and the image characteristics are provided in the metadata file of the bands.

A number of 6 Landsat8 images acquired from TIRS sensor (Table 2) have been used in this study from different months and seasons during the year of 2017.
The used images were cloud free in order to get an accurate reflected light of the earth surface.

Table 1. Thermal constants and Rescaling factors in Landsat 8TIRS

\begin{tabular}{|c|c|c|c|c|}
\hline \multirow{2}{*}{$\begin{array}{c}\text { Thermal } \\
\text { Bands }\end{array}$} & \multicolumn{2}{|c|}{ Thermal constant } & \multicolumn{2}{c|}{ Rescaling Factor } \\
\cline { 2 - 5 } & $\mathrm{K} 1$ & $\mathrm{~K} 2$ & $\mathrm{ML}_{\mathrm{L}}$ & $\mathrm{A}_{\mathrm{L}}$ \\
\hline Band 10 & 774.8853 & 1321.0789 & $3.3420 \mathrm{E}-04$ & 0.10000 \\
\hline
\end{tabular}

Table 2. TIRS images used for SST estimation

\begin{tabular}{lccc}
\hline \multicolumn{1}{c}{ Satellite ID } & Path/Row & $\begin{array}{c}\text { Acquisition } \\
\text { date }\end{array}$ & $\begin{array}{c}\text { Acquisition } \\
\text { time }\end{array}$ \\
\hline LC08_L1TP_201035_2017 & $201 / 35$ & 23 Apr2017 & $10: 56: 08$ \\
0423_20180527_01_T1 & & & \\
LC08_L1TP_201035_2017 & $201 / 35$ & 26 Jun 2017 & $10: 56: 32$ \\
0626_20170714_01_T1 & & & \\
LC08_L1TP_201035_2017 & $201 / 35$ & 28 Jul 2017 & $10: 56: 42$ \\
0728_20170810_01_T1 & & & \\
LC08_L1TP_201035_2017 & $201 / 35$ & 14 Sep 2017 & $10: 56: 52$ \\
0914_20170928_01_T1 & & & \\
LC08_L1TP_201035_2017 & $201 / 35$ & 17 Nov 2017 & $10: 57: 00$ \\
1117_20171122_01_T1 & & & \\
LC08_L1TP_201035_2017 & $201 / 35$ & 19 Dec 2017 & $10: 56: 58$ \\
1219_20171224_01_T1 & & & \\
\hline
\end{tabular}

Landsat 8 data processing started with a radiometric correction which aims to convert digital number (DN) values in thermal bands to the top of atmosphere spectral radiance values (1) using the rescaling factors (USGS 2015) [11] as follows:

$$
L_{\lambda}=M_{L} \times Q_{c a l}+A_{L}
$$

Where:

$\mathrm{L}_{\lambda}=$ TOA spectral radiance $($ Watts $/(\mathrm{m} 2 * \operatorname{srad} * \mu \mathrm{m}))$

$\mathrm{M}_{\mathrm{L}}=$ Band-specific multiplicative rescaling factor

$\mathrm{A}_{\mathrm{L}}=$ Band-specific additive rescaling factor

$\mathrm{Q}_{\text {cal }}=$ Quantized and calibrated standard product pixel values

In this paper, the radiative transfer equation-based method was used for thermal Infrared Sensor TIRS to retrieve Sea surface temperature (SST). The radiance received by the channel at the level of the sensor measured the radiant energy emitted by the ground in addition to the downwelling and the upwelling path radiances characterizing the atmospheric effects on the radiation transfer.

The determination and the calculation of SST reflected by the earth surface require the removal of atmospheric effects due to scattering and absorption. 
A simplified radiative transfer equation (2) was used as an atmospheric correction algorithm to estimate ground radiance received by the TIRS sensor at a specific temperature value can be expressed as:

$$
B_{i}\left(T_{i}\right)=\tau_{i}(\theta)\left[\varepsilon_{i} B_{i}\left(T_{s}\right)+\left(1-\varepsilon_{i}\right) I_{i}{ }^{\downarrow}\right]+I_{i}^{\uparrow}
$$

Where:

$B_{i}\left(T_{i}\right):$ the radiance received by channel $i$ of the sensor with brightness temperature $T i$, the detail of the TIRS' calibration can be found at USGS Landsat Project website.

$B_{i}\left(T_{s}\right)$ : The ground radiance

$\tau_{i}(\theta):$ Atmospheric transmittance for channel $i$ when view zenith angle is $\theta$. TIRS is treated as nadir viewing since the view angle is no more than $7.5^{\circ}[12]$.

$\varepsilon_{i} \quad$ : Surface emissivity for channel $i$

For the radiative transfer algorithm, the atmospheric profile was extracted from the NCEP data set; the Atmospheric Correction Parameter calculator located on the web at (https://atmcorr.gsfc.nasa.gov/) was used to simulate atmospheric transmittance as well as to obtain downwelling and upwelling radiance (Figure 2).

The Parameter Calculator requires a specific date, time, and location as input and allows the user to select how the modeled atmospheric profile is interpolated [13].

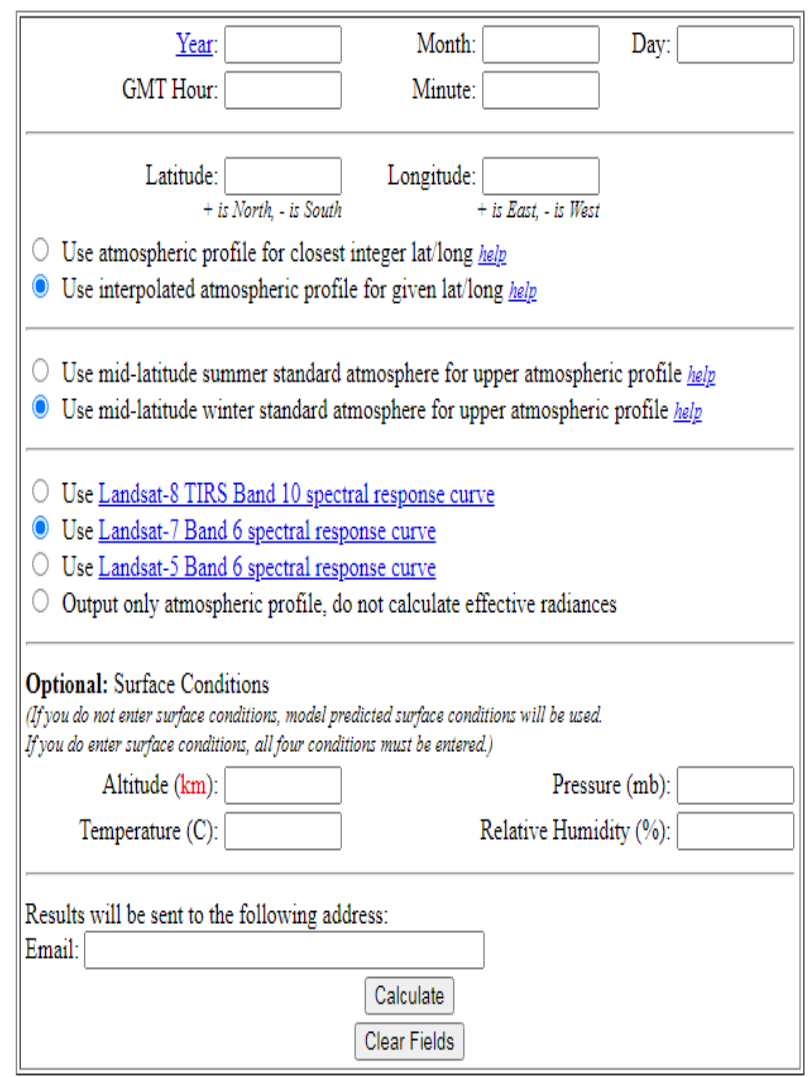

Figure 2. Atmospheric correction parameter calculator interface
With the thermal radiance determined at the Landsat 8 sensor level, accompany by the atmospheric parameters obtained with the Atmospheric Correction Parameter Calculator, the Sea Surface Temperature can be calculated according to the equation (3):

$$
T S=\frac{K 2}{\ln \left(1+\frac{K 1}{B_{i}}\right)}
$$

Where $\mathrm{K}_{1}$ and $\mathrm{K}_{2}$ are the Band-specific thermal conversion constants provided in the metadata file MTL delivered with the USGS Landsat level-1 data products (Table 1). Sea Surface Temperature values estimated from the Sensor TIRS images were compared with insitu samples measurements for testing the accuracy of the developed equations using a simple correlation method.

\subsection{Statistical analysis}

The correlation techniques are widely used for testing the strength of the relationship between two quantitative variables. The correlation analysis quantifies the strength of the relationship between measured sea surface temperature values and remotely sensed data of sea surface temperature in the study area. In the present study, four factors were used to test the accuracy of Landsat 8 data obtained from thermal band 10: p-value, Adjusted Square Correction $\left(\mathrm{R}^{2}\right)$, Root Mean Square Error (RMSE), standard error of the estimate (SEE) calculated as follows [14] $(4,5,6)$ :

$$
R^{2}=\left(\frac{n \sum(y)-\left(\sum x\right)\left(\sum y\right)}{\sqrt{n\left(\sum x^{2}\right)-\left(\sum x\right)^{2}} \sqrt{n\left(\sum y^{2}\right)-\left(\sum y\right)^{2}}}\right)^{2}
$$

Where:

$\mathrm{x}=$ the estimated sea surface temperature $\mathrm{y}=$ the measured sea surface temperature $\mathrm{n}=$ Total point

$$
R M S E=\sqrt{\frac{\sum_{i=1}^{n}(\text { Xesti-Xmeans })^{2}}{N}}
$$

Where:

$\mathrm{X}_{\text {esti }}=$ the estimated value of the sea surface temperature using the algorithm

$\mathrm{X}_{\text {means }}=$ the measured value of the surface temperature using a thermometer

$\mathrm{N} \quad=$ total point

Where:

$$
\sigma e s t=\sqrt{\frac{\sum_{i=1}^{n}(Y-Y e s t i)^{2}}{N}}
$$

$\mathrm{Y}=$ the calculated value of the sea surface temperature using TIRS data

$\mathrm{Y}_{\text {esti }}=$ the estimated value of the surface temperature from the regression

$\mathrm{N} \quad=$ total point 
The $p$-value is a statistical measure that can determine the significant terms in a developed model. In other words, $p$-value (or significance sig.) indicates the possible variability of the outputs following changes in the predictors [15]. A lower p-value $(<0.001)$ can be, a better model can result. A normality test is conducted as well to study the distribution of residuals.

For the generation of the mathematical equations and the correlation analysis, the Statistical Package of the Social Sciences (SPSS) software was used to evaluate the data of this current study. SNAP software and ArcGIS were used to do the image processing and to create the spatial distribution maps for the water parameters in the coastline of Tangier-Ksar Sghir region.

\section{Results and discussion}

The study of the potential of remote sensing in estimating water temperature has attracted many authors such as Pivato et al. (2019) [16], Cherif et al. (2019) [17], Abdelmalik (2016) [18], Syariz et al. (2015) [19], Lamaro et al. (2012) [20], Handcock et al. (2012) [21], and Ahn et al. (2006) [22].

The current work used the TIRS thermal band to retrieve seawater temperature (SST) from the radiative transfer equation-based method. The elaborated algorithm allowed to estimate SST from the Landsat8 data for seawater in the coastline of Tangier-Ksar Sghir region during the year 2017 .

A total of 25 sampling points were used to measure the water temperature in-situ simultaneously with the Landsat processed data to examine the relationship between the calculated values and the measured ones. Figure 3 illustrates the results of the developed equations for correlating water temperature using TIRS data and in-situ measurements.

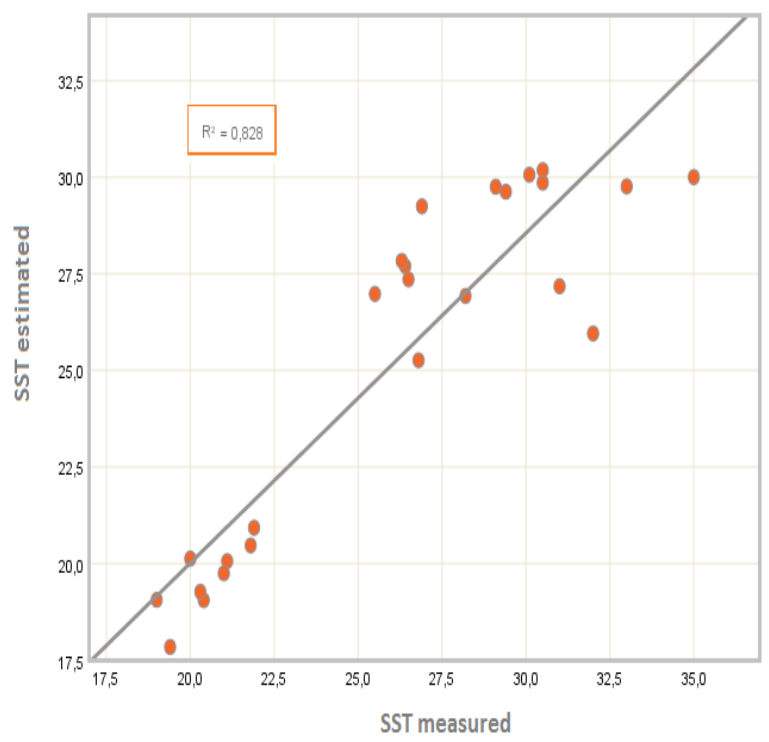

Figure 3. Relational plot of the measured parameters values vs. the estimated ones
The linear regression showed a high determination coefficient $\left(\mathrm{R}^{2}=0.828\right)$ between the in-situ values and the calculated ones. By examining the analysis of variance (ANOVA) results, a low p-value was found $($ sig. $<0.001)$ which means the model is statistically significant.

The correlation coefficient obtained indicated as well as good results in terms of measuring the accuracy of the algorithm. By calculating the error coefficients, we obtained considerably low values $(\mathrm{RMSE}=2.142$, $\mathrm{SEE}=1.909$ ) and that can express a good accuracy between observed and predicted data.

A probability test called P-P plot was conducted as well in order to assess graphically the normality of data distribution. The P-P plot aims to compare the observed cumulative distribution function of the standardized residual to the expected cumulative distribution function of the normal distribution [23].

The test is basically examining the normality of the residuals and not the predictors. By observing the normal p-p plots of water temperature regression (Figure 4) the data fall along the diagonal line and is shaped like a normal curve which means statistically is normally distributed.

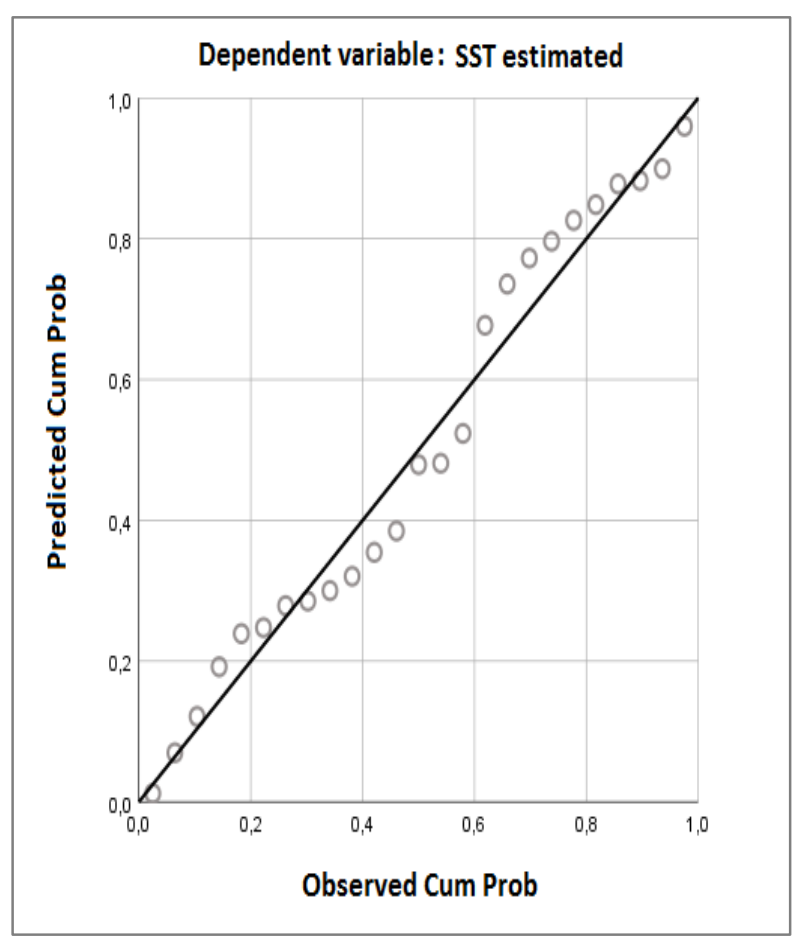

Figure 4. Probability p-p plot for SST residuals

The spatial distribution of the estimated temperature from the samples collected from 10 areas of the study region is showed in Figure 5.

Various temperature levels and values were seen between the areas of the study region over the year 2017. The distribution maps showed an increase of temperature along the coastline unlikely by moving away from the shore to the sea. 

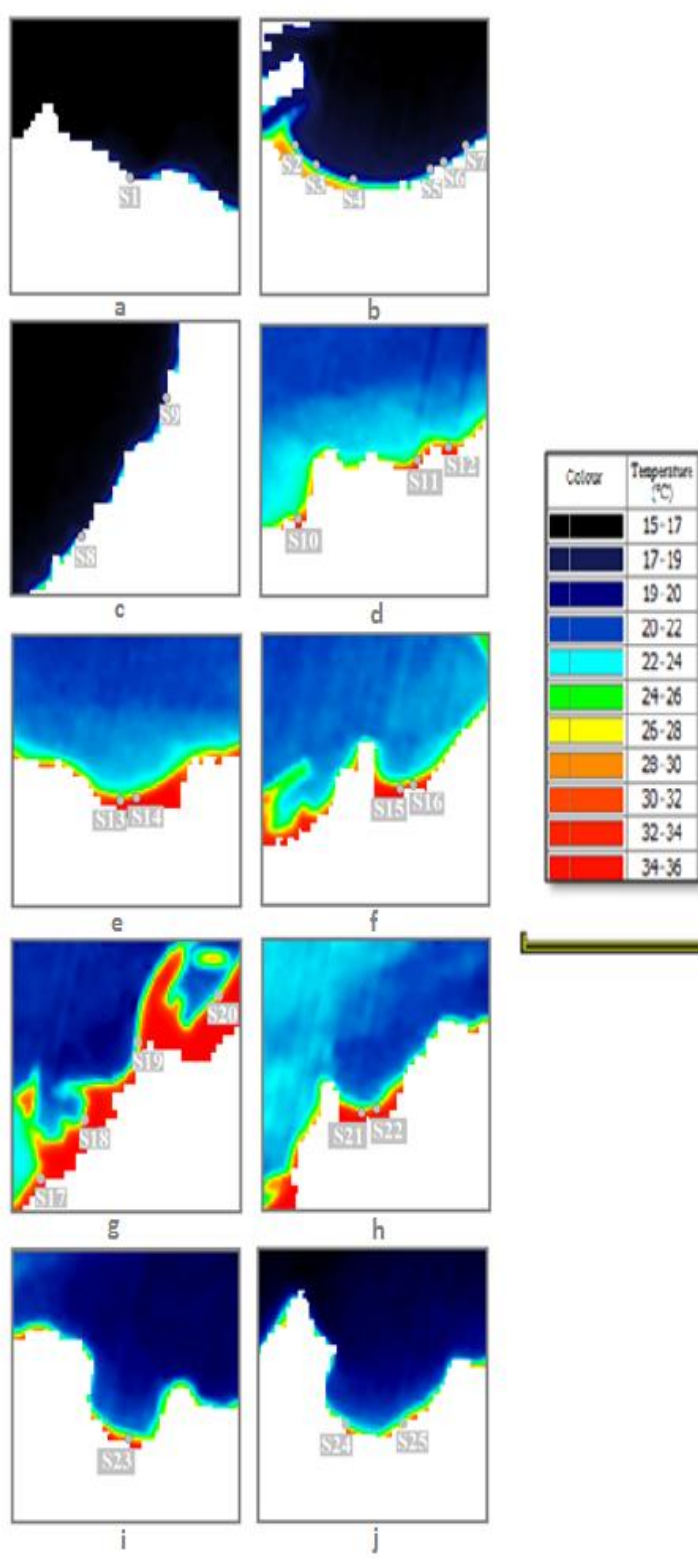

Figure 5. Spatial distribution of water temperature in the region of Tangier-Ksar Sghir during 2017

The highest values of SST were observed in the region of the port of Tanger Med (area $\mathrm{j}$ ). The four samples sites at the area g: S17, S18, S19, and S20 showed high SST values ranging between $27^{\circ} \mathrm{C}$ and 30 ${ }^{\circ} \mathrm{C}$ comparing to the sites S24 and S25 located at the Benyounech beach (area $\mathrm{j}$ ) which showed the lower values $\left(26^{\circ} \mathrm{C}\right.$ as an average value). The port area is characterized by various industrial and trade activities including distribution transportation and the use of chemical products and contaminants such as nutrients while interacting affect the water column temperature [24]. The five areas (area d, area e, area f, area i, and area h) showed divergent values except for site S15 situated in the Ksar Sghir beach that presented lower values $\left(27^{\circ} \mathrm{C}\right)$. The three areas $\mathrm{a}, \mathrm{b}$, and c located at the west part of the study region include Merqala beach (S1), municipal beach (S2, S3, and S4), and the Malabata beach (S5, S6, and S7) respectively were characterized by different values that oscillate between $19^{\circ} \mathrm{C}$ and $21^{\circ}$. The results are showing high values of SST at the municipal beach. The pretreatment station and the Tangier port discharges also the effluents of the Souani and Meghougha oueds flow and drain into the sea nearby the municipal beach which affects directly the quality of waters in the area in accordance with what it was found in our previous study that aimed to assess coastal water quality using a statistical approach. [25].

\section{Conclusion}

The present paper illustrates and proves the presence of a significant relation between TIRS thermal band data and the measured sea surface temperature values. The results obtained from the statistical analysis showed a high determination coefficient between the in-situ temperature values and the predicted ones. The residuals analysis showed as well good results while testing the homogeneity of variance for the linear regression Therefore, The sea surface temperature obtained from reflectance bands enables an accurate estimation for the SST based on a radiative transfer equation.

The results show that the application of remote sensing techniques combined with traditional in situ temperature measurements to evaluate the accuracy can provide reliable information on temperature, besides, the remote sensing techniques can be developed to be more accurate and precise for absolute estimation of seawater temperature.

\section{References}

1. [1] Agardy, Tundi and Jacqueline Alder (Coordinating Lead Authors), 2005, "Coastal Systems," chapter 19 in Rashin Hassan, Robert Scholes, and Neville Ash, eds, Ecosystemsand Human Well-Being: Current State and Trends, Volume 1, Washington, DC: Island Press.

2. [2] M. Gholizadeh, A. Melesse, et L. Reddi, «A Comprehensive Review on Water Quality Parameters Estimation Using Remote Sensing Techniques », Sensors, vol. 16, nº 8, p. 1298, août 2016.

3. [3] A. Prakash, «THERMAL REMOTE SENSING: CONCEPTS, ISSUES AND APPLICATIONS », Part B, p. 5.

4. [4] I. Bourouhou, F. Salmoun, et Y. Gedik, «Characteristics of Mediterranean Sea Water in Vicinity of Tangier Region, North of Morocco », Proceedings, vol. 2, $\mathrm{n}^{\mathrm{O}}$ 20, p. 1291, oct. 2018, doi: $10.3390 /$ proceedings 2201291 .

5. [5] A. Laghzal et al., «Evaluation of physicochemical and bacteriological quality of water springs by using a principal component analysis (PCA): A case study of Tingitane Peninsula (Morocco) », p. 8, 2016. 
6. [6] M.Stefouli et al. Remote sensing techniques as a tool for detecting water outflows. The case study of Cephalonia Island. Bulletin of the Geological Society of Greece.Vol 47, p.1519, 2013.

7. [7] M. Haakstad, J. W. Kogeler, et S. Dahle, "Studies of sea surface temperatures in selected northern Norwegian fjords using Landsat TM data », Polar Research, vol. 13, $\mathrm{n}^{\circ}$ 1, p. 95-10, 1994, doi: https://doi.org/10.1111/j.1751-8369.1994.tb00440.x.

8. [8] J. M. ANDERSON et S. B. WILSON, «Review Article.The physical basis of current infrared remote-sensing techniques and the interpretation of data from aerial surveys », null, vol. 5, $\mathrm{n}^{\mathrm{o}} 1$, p. 1-18, janv. 1984, doi: $10.1080 / 01431168408948786$.

9. [9] T. Dev Acharya. Exploring La,dsat 8 . International Journal of IT, Engineering and Applied Sciences Research (IJIEASR)

10. Volume 4, No. 4, April 2015

11. [10] C. T. Pinto, X. Jing, et L. Leigh, « Evaluation Analysis of Landsat Level-1 and Level-2 Data Products Using In Situ Measurements », p. 30, 2020.

12. [11] Using the USGS Landsat Level-1 Data Product. Site: https://www.usgs.gov/core-sciencesystems/nli/landsat/using-usgs-landsat-level-1-dataproduct.

13. [12] X. Yu, X. Guo, et Z. Wu, «Land Surface Temperature Retrieval from Landsat 8 TIRSComparison between Radiative Transfer EquationBased Method, Split Window Algorithm and Single Channel Method », Remote Sensing, vol. 6, $\mathrm{n}^{\circ}$ 10, p. 9829-9852, oct. 2014, doi: 10.3390/rs6109829.

14. [13] Atmospheric Correction Parameter Calculator. Site: https://atmcorr.gsfc.nasa.gov/.

15. [14] Correlation and regression. Class Note. Site: http://www.biostat.jhsph.edu/ iruczins/teaching/390 $.672 /$ notes/notes.class6.

16. [15] C. Andrade, "The P Value and Statistical Significance: Misunderstandings, Explanations, Challenges, and Alternatives », Indian J Psychol Med, vol. 41, $\mathrm{n}^{\mathrm{o}}$ 3, p. 210-215, 2019, doi: 10.4103/IJPSYM.IJPSYM_193_19.

17. [16] M. Pivato, L. Carniello, D. P. Viero, C. Soranzo, A. Defina, et S. Silvestri, «Remote Sensing for Optimal Estimation of Water Temperature Dynamics in Shallow Tidal Environments », Remote Sensing, vol. 12, $\mathrm{n}^{\circ}$ 1, p. 51, déc. 2019, doi: 10.3390/rs12010051.

18. [17] E. K. Cherif, F. Salmoun, et F. J. MesasCarrascosa, «Determination of Bathing Water Quality Using Thermal Images Landsat 8 on the West Coast of Tangier: Preliminary Results », Remote Sensing, vol. 11, no 8, p. 972, avr. 2019, doi: 10.3390/rs11080972.

19. [18] K. W. Abdelmalik, «Role of statistical remote sensing for Inland water quality parameters prediction », The Egyptian Journal of Remote Sensing and Space Science, vol. 21, $\mathrm{n}^{\mathrm{o}}$ 2, $\mathrm{p}$.
193-200
sept.
2018 ,
doi:

10.1016/j.ejrs.2016.12.002.

20. [19] M. A. Syariz, L. M. Jaelani, L. Subehi, A. Pamungkas, E. S. Koenhardono, et A. Sulisetyono, «RETRIEVAL OF SEA SURFACE TEMPERATURE OVER POTERAN ISLAND WATER OF INDONESIA WITH LANDSAT 8 TIRS IMAGE: A PRELIMINARY ALGORITHM », Int. Arch. Photogramm. Remote Sens. Spatial Inf. Sci., vol. XL-2/W4, p. 87-90, oct. 2015, doi: 10.5194/isprsarchives-XL-2-W4-872015.

21. [20] A. A. Lamaro, A. Mariñelarena, S. E. Torrusio, et S. E. Sala, «Water surface temperature estimation from Landsat 7 ETM+ thermal infrared data using the generalized single-channel method: Case study of Embalse del Río Tercero (Córdoba, Argentina) », Advances in Space Research, vol. 51, $\mathrm{n}^{\mathrm{o}} \quad 3$, p. 492-500, févr. 2013, doi: 10.1016/j.asr.2012.09.032.

22. [21] R. N. Handcock et al., «Thermal Infrared Remote Sensing of Water Temperature in Riverine Landscapes », in Fluvial Remote Sensing for Science and Management, P. E. Carbonneau et H. Piégay, Éd. Chichester, UK: John Wiley \& Sons, Ltd, 2012, p. 85-113.

23. [22] Y.-H. Ahn, P. Shanmugam, J.-H. Lee, et Y. Q. Kang, «Application of satellite infrared data for mapping of thermal plume contamination in coastal ecosystem of Korea », Marine Environmental Research, vol. 61, n ${ }^{\circ}$ 2, p. 186-201, mars 2006, doi: 10.1016/j.marenvres.2005.09.001

24. [23] Introduction to Regression with SPSS Lesson 2: SPSS Regression Diagnostics ». Site: https://stats.idre.ucla.edu/spss/seminars/introduction -to-regression-with-spss/introreg-lesson2/.

25. [24] M. Gholizadeh, A. Melesse, et L. Reddi, « A Comprehensive Review on Water Quality Parameters Estimation Using Remote Sensing Techniques », Sensors, vol. 16, nº 8, p. 1298, août 2016.

26. [25] I. Bourouhou. Utilisation de l'analyse en composantes principales (ACP) pour l'évaluation de la qualité sanitaire des eaux le long du littoral méditerranéen dans la région de Tanger-Ksar Sghir, Maroc , Revue EIN, mars 28, 2019. 